\title{
Portfolio Return Characteristics of Different Industries
}

\author{
Igor Pouchkarev, Jaap Spronk, Pim van Vliet
}

\begin{tabular}{|l|l|}
\hline \multicolumn{2}{|l|}{ ERIM REPORT SERIES RESEARCH IN MANAGEMENT } \\
\hline ERIM Report Series reference number & ERS-2003-014-F\&A \\
\hline Publication status / version & February 2003 \\
\hline Number of pages & 16 \\
\hline Email address corresponding author & spronk@few.eur.nl \\
\hline Address & Erasmus Research Institute of Management (ERIM) \\
& Rotterdam School of Management / Faculteit Bedrijfskunde \\
& Erasmus Universiteit Rotterdam \\
& PoBox 1738 \\
& 3000 DR Rotterdam, The Netherlands \\
& Phone: \# 31-(0) 10-408 1182 \\
& Fax: \# 31-(0) 10-408 9640 \\
& Email: info@erim.eur.nl \\
& Internet: www.erim.eur.nl \\
\hline
\end{tabular}

Bibliographic data and classifications of all the ERIM reports are also available on the ERIM website: www.erim.eur.nl 


\title{
ERASMUS RESEARCH INSTITUTE OF MANAGEMENT
}

\author{
REPORT SERIES
}

RESEARCH IN MANAGEMENT

\begin{tabular}{|c|c|c|}
\hline \multicolumn{3}{|c|}{ BIBLIOGRAPHIC DATA AND CLASSIFICATIONS } \\
\hline Abstract & \multicolumn{2}{|c|}{$\begin{array}{l}\text { Over the last decade we have witnessed the rise and fall of the so-called new economy stocks. } \\
\text { One central question is to what extent these new firms differ from traditional firms. Empirical } \\
\text { evidence suggests that stock returns are not normally distributed. In this article we investigate } \\
\text { whether this also holds for portfolios of stocks from a growth industry. Furthermore, we will } \\
\text { compare this type of portfolios with portfolios of stocks from a more traditional industry. Usually, } \\
\text { only value weighted and equally weighted portfolios are used to describe and compare portfolio } \\
\text { return characteristics. Instead, in our analysis, we use a novel approach in which we use an } \\
\text { infinite number of portfolios that together represent the set of all feasible portfolio opportunities. }\end{array}$} \\
\hline \multirow{3}{*}{$\begin{array}{l}\text { Library of Congress } \\
\text { Classification } \\
\text { (LCC) }\end{array}$} & $5001-6182$ & Business \\
\hline & $4001-4280.7$ & Finance Management, Business Finance, Corporation Finance \\
\hline & HG4636 & Stock price indexes \\
\hline \multirow{5}{*}{$\begin{array}{l}\text { Journal of Economic } \\
\text { Literature } \\
\text { (JEL) }\end{array}$} & M & Business Administration and Business Economics \\
\hline & G 3 & Corporate Finance and Governance \\
\hline & C 15 & Statistical Simulation Methods; Monte Carlo Methods \\
\hline & C 43 & Index Numbers and Aggregation \\
\hline & G 10 & General Financial Markets: General \\
\hline \multirow{3}{*}{$\begin{array}{l}\text { European Business Schools } \\
\text { Library Group } \\
\text { (EBSLG) }\end{array}$} & $85 \mathrm{~A}$ & Business General \\
\hline & $220 \mathrm{~A}$ & Financial Management \\
\hline & $220 \mathrm{Q}$ & Stock and bond markets \\
\hline \multicolumn{3}{|c|}{ Gemeenschappelijke Onderwerpsontsluiting (GOO) } \\
\hline \multirow[t]{3}{*}{ Classification GOO } & 85.00 & Bedrijfskunde, Organisatiekunde: algemeen \\
\hline & 85.30 & Financieel management, financiering \\
\hline & 85.33 & Beleggingsleer \\
\hline \multirow[t]{3}{*}{ Keywords GOO } & \multicolumn{2}{|c|}{ Bedrijfskunde / Bedrijfseconomie } \\
\hline & \multicolumn{2}{|c|}{ Accountancy, financieel management, bedrijfsfinanciering, besliskunde } \\
\hline & \multicolumn{2}{|c|}{ Effectenhandel, Indices, Prestatiebeoordeling, Duitsland, } \\
\hline Free keywords & \multicolumn{2}{|c|}{ portfolio management, investments, stock markets, sector index, performance evaluation } \\
\hline
\end{tabular}




\title{
Portfolio Return Characteristics of Different INDUSTRIES
}

\author{
Igor Pouchkarev ${ }^{1}$ Jaap Spronk ${ }^{2}$ Pim van Vliet ${ }^{3}$ *
}

\begin{abstract}
Over the last decade we have witnessed the rise and fall of the so-called new economy stocks. One central question is to what extent these new firms differ from traditional firms. Empirical evidence suggests that stock returns are not normally distributed. In this article we investigate whether this also holds for portfolios of stocks from a growth industry. Furthermore, we will compare this type of portfolios with portfolios of stocks from a more traditional industry. Usually, only value weighted and equally weighted portfolios are used to describe and compare portfolio return characteristics. Instead, in our analysis, we use a novel approach in which we use an infinite number of portfolios that together represent the set of all feasible portfolio opportunities.
\end{abstract}

Rotterdam, 5 February 2003

\footnotetext{
${ }^{1}$ Erasmus University Rotterdam, Rotterdam, The Netherlands, pouchkarev@few.eur.nl

${ }^{2}$ Erasmus University Rotterdam, Rotterdam, The Netherlands, spronk@few.eur.nl

${ }^{3}$ Erasmus University Rotterdam, Rotterdam, The Netherlands, wvanvliet@few.eur.nl

* The authors like to thank the participants and discussants at the "Managing Enterprises of the New Economy by Modern Concepts of the Theory of the Firm" conference in Hagen, Germany, and Danny Vlasblom for helping them with a part of the computational work. As usual, all remaining errors are the responsibility of the authors.
} 


\section{INTRODUCTION}

Over the last decade we have witnessed the rise and fall of the so-called new economy stocks. The price movement of the listed growth stocks can be characterized by boom and bust. The surge of stock prices in the late nineties and the dramatic fall in the new millennium has fascinated many, inside and outside academia.

The environment in which new economy firms operate is characterized by rapid technological change and dynamic interaction. Flexibility in decision-making is necessary for survival and can be seen as a core competence. Fitted within the twodimensional BCG matrix new economy stocks represent the 'stars' or 'question marks', where the old economy stocks represent 'dogs' or 'cash cows'. What these new stocks and new industries characterize is their growth potential, which largely determines their value. Growth potential depends on firm specific and industry specific factors: e.g. management's capability to identify and exploit valuable growth options, or the number of strategic alliances, and the rate of technological change within an industry. It remains a challenge to appropriately determine the correct value of this growth potential. Real options analysis, e.g. (Kester 1984; Trigeorgis 1996), could help, for it reckons with managers flexibility to alter decisions.

Ultimately, growth potential of firms influences the risk return profile of their cash flows. Projects or activities can be abandoned if conditions turn out unfavorable. This limits downside risk. On the other hand, successful projects can be expanded, thus leaving upside potential open. Because of this flexibility the distribution of the growth company's expected cash flows is characterized by asymmetry. The distribution characteristics of a firm's cash flows are of course not automatically valid descriptions of the firm's stock return characteristics. Firstly, the market has its own perception of the firm's cash flows (e.g. due to information asymmetries). Secondly, after interest payments only a residual of the cash flows goes to the stock owners. Therefore the degree of financial leverage affects the pay-off structure and could also introduce asymmetry in stock returns. Thirdly the market has the possibility of diversification, which means that, in general, not all cash flow risk is priced.

If cash flow distributions are not symmetrical, the stock return distributions may well be. However, empirical research shows that stock returns are not normally distributed (Fama 1965; Kon 1984). The fat tail phenomenon is well documented and, in addition, there is evidence of positive skewness in the distributions of small growth stocks (Knez and Ready 1997). Not only individual stocks returns, but also market indices are characterized by asymmetry. Several studies (Kraus and Litzenberger 1976; Harvey and Siddique 2000) have demonstrated that systematic skewness is priced as market risk.

The present article examines the different portfolio return characteristics of a new economy industry versus an old economy industry. Usually indices, either market value weighted or equally weighted, are used to describe and compare portfolio return characteristics. However, if seen as investment strategies that can actually be implemented, fund managers do have many alternatives for tracking specific indices. Some select stocks based on fundamental analysis or technical analysis, others follow passive strategies. Therefore, the composition of a fund manager's portfolio is often different from one of the usual indices. Actually, with the same components of the usual 
indices, an infinite number of portfolios can be constructed. Using a novel approach (Hallerbach et al. 2002; Pouchkarev 2004) the set of all feasible portfolios with the same components can be simulated. We will take a closer look at all feasible portfolio opportunities and examine to what extent the portfolio opportunity set of high potential stocks differs from the portfolio opportunity set of traditional stocks.

The article proceeds as follows. In section two we will describe the methodology and the return data of two industries, semiconductors and mining. In section three we provide the statistics of our analyses and discuss the results. Finally section four concludes.

\section{Methodology}

\section{Set of Portfolio Opportunities}

The main idea of the approach chosen in the present article is to explore the whole set of portfolio formation opportunities in an industry instead of limiting to separate portfolios and industry indices. We estimate the distribution of the ex post performance values (e.g. average return, variance, semivariance etc.) of all possible portfolios that can be composed from stocks listed within the industry. The development of the location of these distributions yields a picture of the average development of the industry over a certain time period. The development of the dispersion of these distributions provides a picture of the development of the industry dynamics over time.

The single restriction we make here, by looking at portfolio opportunities in an industry, is the exclusion of short sales. Then the opportunity set (where 'opportunity' is viewed in retrospection) consists of all portfolios within the same industry sector with weights

$$
0 \leq w_{i} \leq 1.0, i=1,2, \ldots, n \text { such that } \sum_{i=1}^{n} w_{i}=1 .
$$

The number of portfolios in the opportunity set is infinite but distributions of portfolio performance values do exist. There are several ways to calculate the required distributions. In this article we use simulation to estimate the distributions. ${ }^{1}$. (We refer to (Hallerbach et al. 2002; Pouchkarev 2004) for further details.) The procedure is as follows:

I. In each simulation step we sample one million feasible random portfolio weight vectors for stocks of the industry concerned. Each sampled weight vector defines a portfolio and is an alternative to invest in the industry. The sampled portfolios are uniformly distributed over the industry portfolio opportunity set;

II. For these sampled portfolios we calculate different portfolio return characteristics: the average rates of return, variances, and semivariances. It is quite easy to extend the number of characteristics, such as mean absolute deviation, Gini index, Herfindahl index, Sharpe ratio, Treynor ratio and many others. These statistics are estimated using 24 observations prior to the actual

\footnotetext{
${ }^{1}$ (i.e. an analytical 'full' representation in some cases, grid procedures and simulation).
} 
evaluation step. For example, by evaluating an industry during November 2000, the stock prices from December 1998 to November 2000 are used;

III. We estimate the frequency distributions of the selected performance measures over the whole portfolio opportunity set of the industry;

IV. The time window is shifted one month forward and the next simulation commences.

\section{Data}

We include the total return data of two different industries: semiconductors and mining. The return is calculated as the monthly percentage increase of the stock price, corrected for dividends and stock splits. The semiconductors industry is supposed to represent the new economy, whereas mining represents an old economy industry. All US firms within the Datastream database ${ }^{1}$ with industrial code 936 (SEMIC) and code 04 (MNING) are selected.

An important issue in this procedure is how to handle changes in the evaluated industry due to new admissions, mergers, bankruptcies etc. In case of a delisting company our strategy is to hold the company security until the last month it was listed. In case of newly admitted companies we insert a company stock into the industry opportunity set as soon as we have 24 monthly price observations. To avoid a survivorship bias all dead and delisted firms, which have had at least 24 months of observations, are also included in our analysis.

Our sample period ranges from December 1980 until January 2001, resulting in a total of 242 months. In December 1980 the Semiconductors sector consists of 12 firms, which number steadily increases to 90 firms in January 2001. The number of firms in the Mining sector increases steadily from 21 in December 1980 to 37 firms in January 2001. Figure 1 shows the exact number of mining and semiconductors firms in each time interval of the evaluation period.

\section{Figure 1: Number of stocks in the semiconductors and mining industries from 1980 through 2001}

For the sample period December 1980 - January 2001, the number of firms in the semiconductors industry increases from 12 in December 1980 to 90 firms in January 2001. In December 1980 there are 21 firms in the Mining sector which number steadily increases to 37 firms quoted in January 2001.

Source: Thomson Datastream

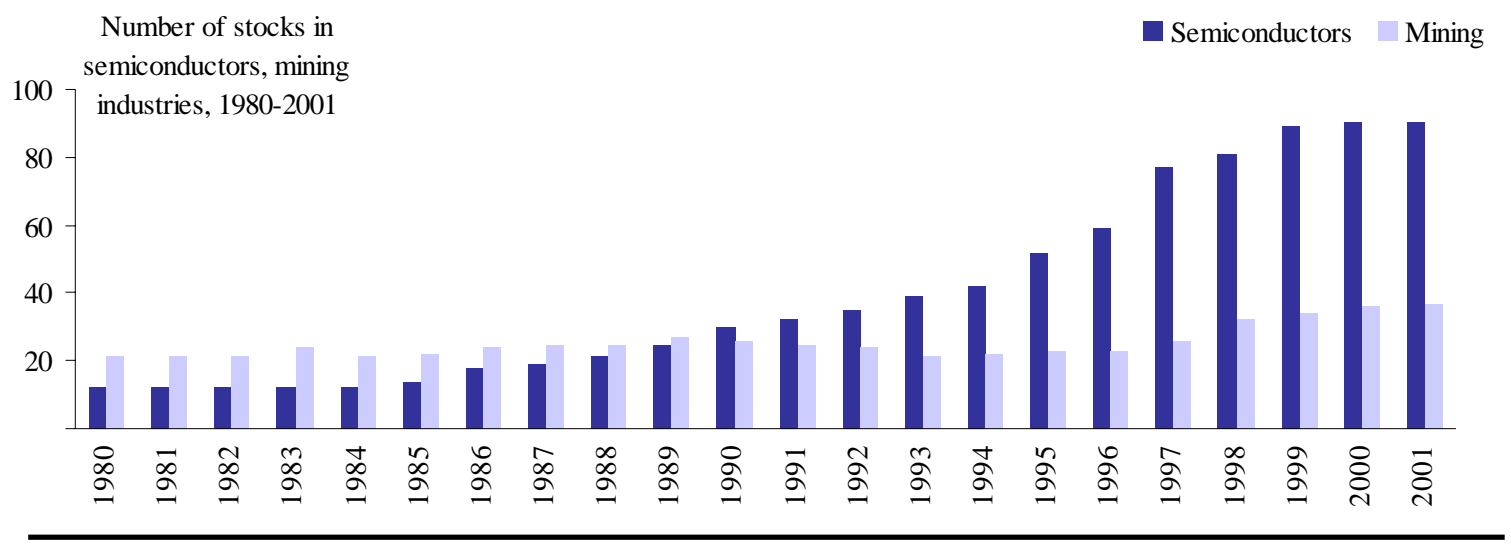

\footnotetext{
${ }^{1}$ Datastream is a part of Thomson Financial
} 


\section{RESULTS}

In Figure 2 we show in Panel A the distribution of the November 1985 returns that results from all the different semiconductors portfolios one could make at the beginning of that month. Panel C shows the returns distribution for November 1995. In addition, the return distributions for mining portfolios are given for November 1985 and November 1995 in panels B and D respectively.

\section{Figure 2: Realized return distributions of semiconductors and mining portfolios for \\ November 1985 and November 1995}

Panel A shows the distribution of returns in November 1985 for portfolios composed from semiconductors stocks (mean 14.236\%). Panel B shows the distribution of returns in the same month for portfolios that are composed from the mining industry stocks (mean $-0.293 \%$ ). Panel C and D give the distributions of returns in November 1995 for the semiconductors portfolios (mean -2.434\%) and the mining portfolios (mean $-7.753 \%$ ). The bin range is $0.005 \%$ in all frequency distributions.

Panel A: Semiconductors, November 1985

Panel B: Mining, November 1985
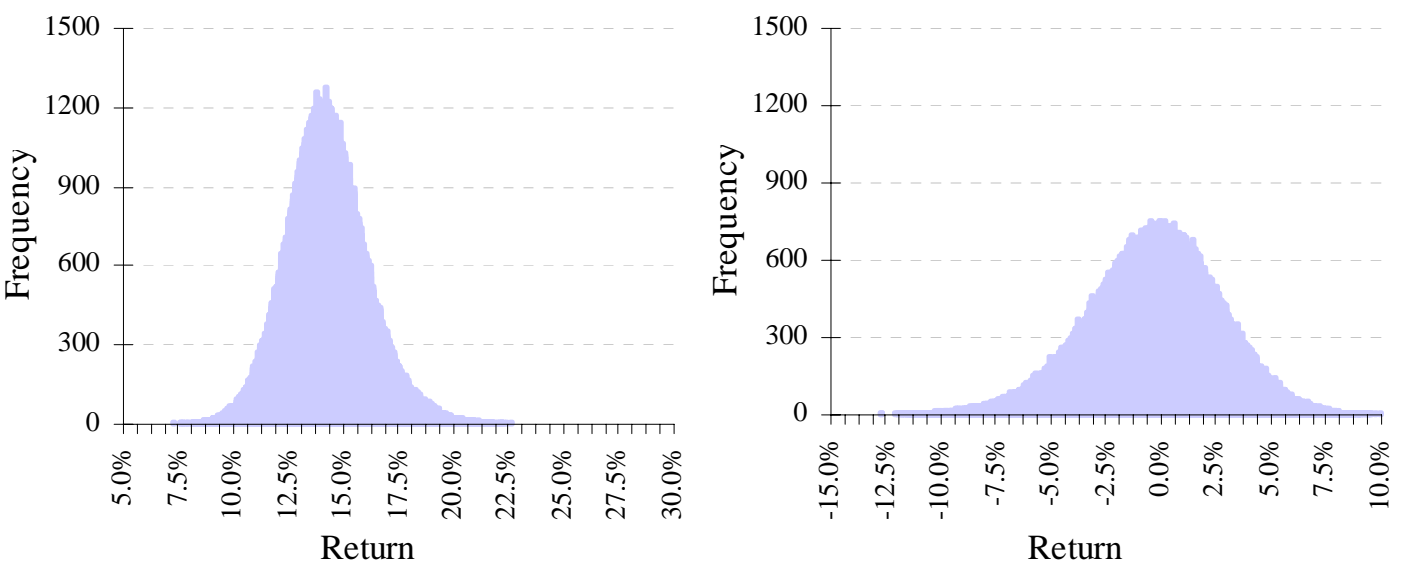

Panel A: Semiconductors, November 1995

Panel B: Mining, November 1995

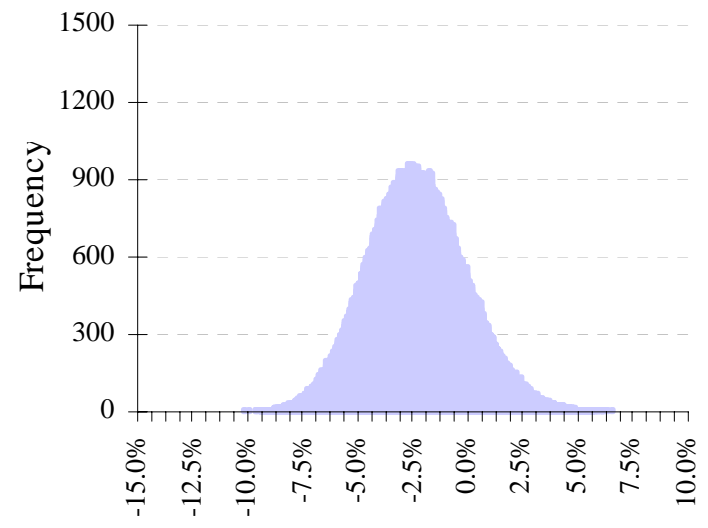

Return

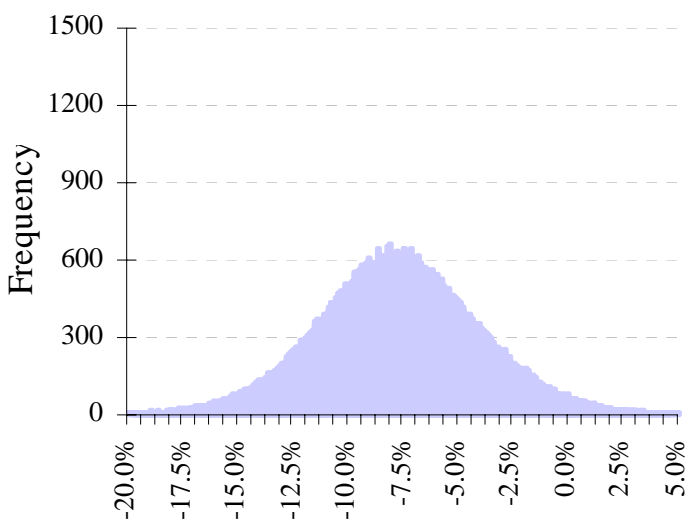

Return

Figure 3 presents in Panel A the distribution of 24-months averages of rate of returns in November 1985, that results from all the different semiconductors portfolios. Panel C shows the average returns distribution for November 1995. In addition, the average return distributions for mining portfolios are given for November 1985 and November 1995 in panels B and D respectively. 


\section{Figure 3: Distributions of 24-months average returns of semiconductors and mining portfolios for November 1985 and November 1995}

Panel A shows the distribution of average returns in November 1985 for portfolios composed from semiconductors stocks (mean 0.007\%). Panel B shows the distribution of average returns in the same month for portfolios that are composed from the mining industry stocks (mean $-0.857 \%$ ). Panel C and D give the distributions of average returns in November 1995 for the semiconductors portfolios (mean $5.372 \%$ ) and the mining portfolios (mean 0.961\%). The bin range is $0.005 \%$ in all frequency

Panel A: Semiconductors, November 1985

Panel B: Mining, November 1985
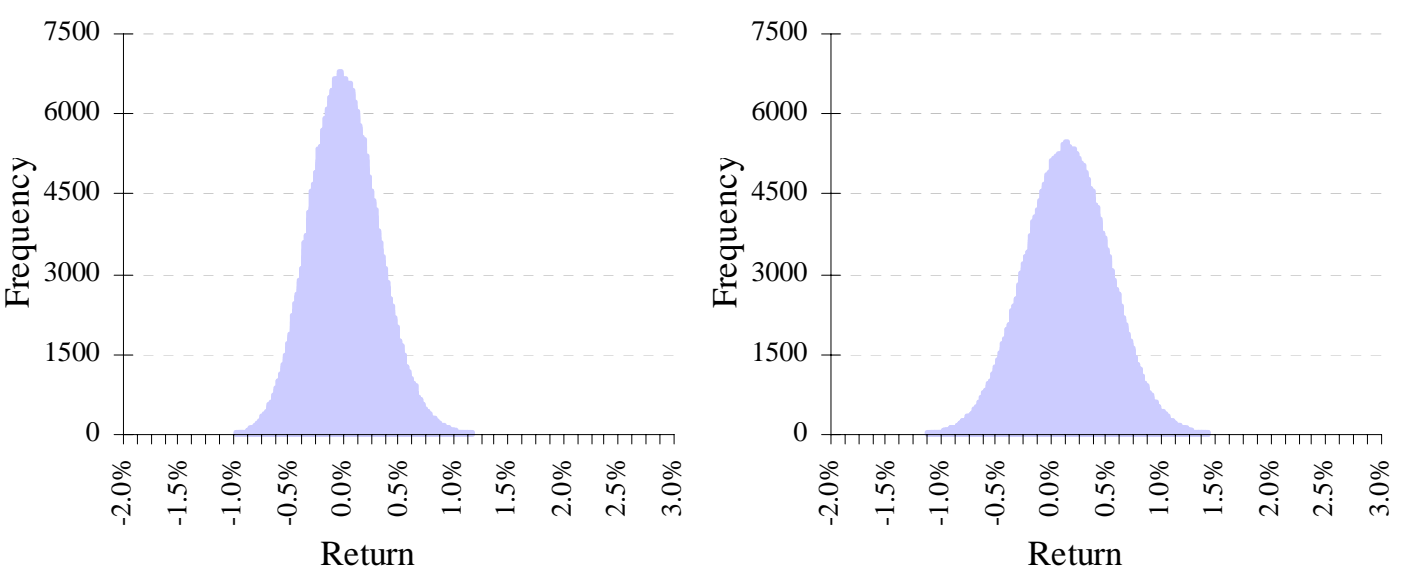

Panel A: Semiconductors, November 1995

Panel B: Mining, November 1995
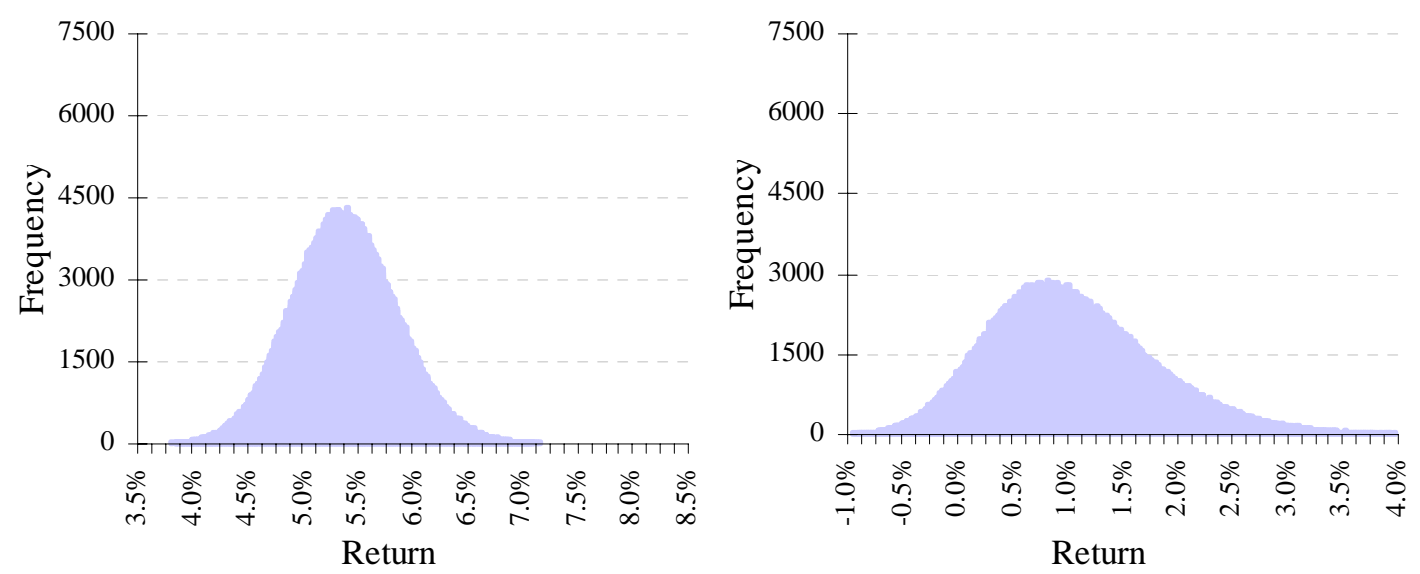

Panel A of Figure 4 graphically shows all 218 (242-24) consecutive return distributions of the semiconductors portfolios, similar to those in Figure 3. For each period, the return distribution is mapped on a vertical bar. The dot on the bar represents the median value of the distribution. The length of the fat bar represents the return range of the middle $50 \%$ of all portfolios. The thin bar (only shown for a few months at the beginning of the period studied) represents the return range capturing all generated portfolios. Panel B of Figure 4 shows the development of the semiconductors portfolio variances. For the comparison of the development in this industry with publicly available indexes, we can only use the Dow Jones US Semiconductors index. ${ }^{1}$ In addition to the distribution summaries, Figure 4 graphs the 24-months moving average

\footnotetext{
${ }^{1}$ This index consists of 81 firms in December 2002.
} 


\section{Figure 4: Distributions of semiconductors portfolios}

For the period December 1982 through January 2001 some statistics of the semiconductor portfolios distribution are presented. Panel A shows the distribution of returns in semiconductors and panel B presents shows the distribution of portfolio variances for the same period. The dot on the bar represents the median value of the distribution. The length of the fat bar represents the return range of the middle 50\% of all portfolios. The thin bar (only shown for a few months at the beginning of the period studied) represents the return range capturing all generated portfolios.
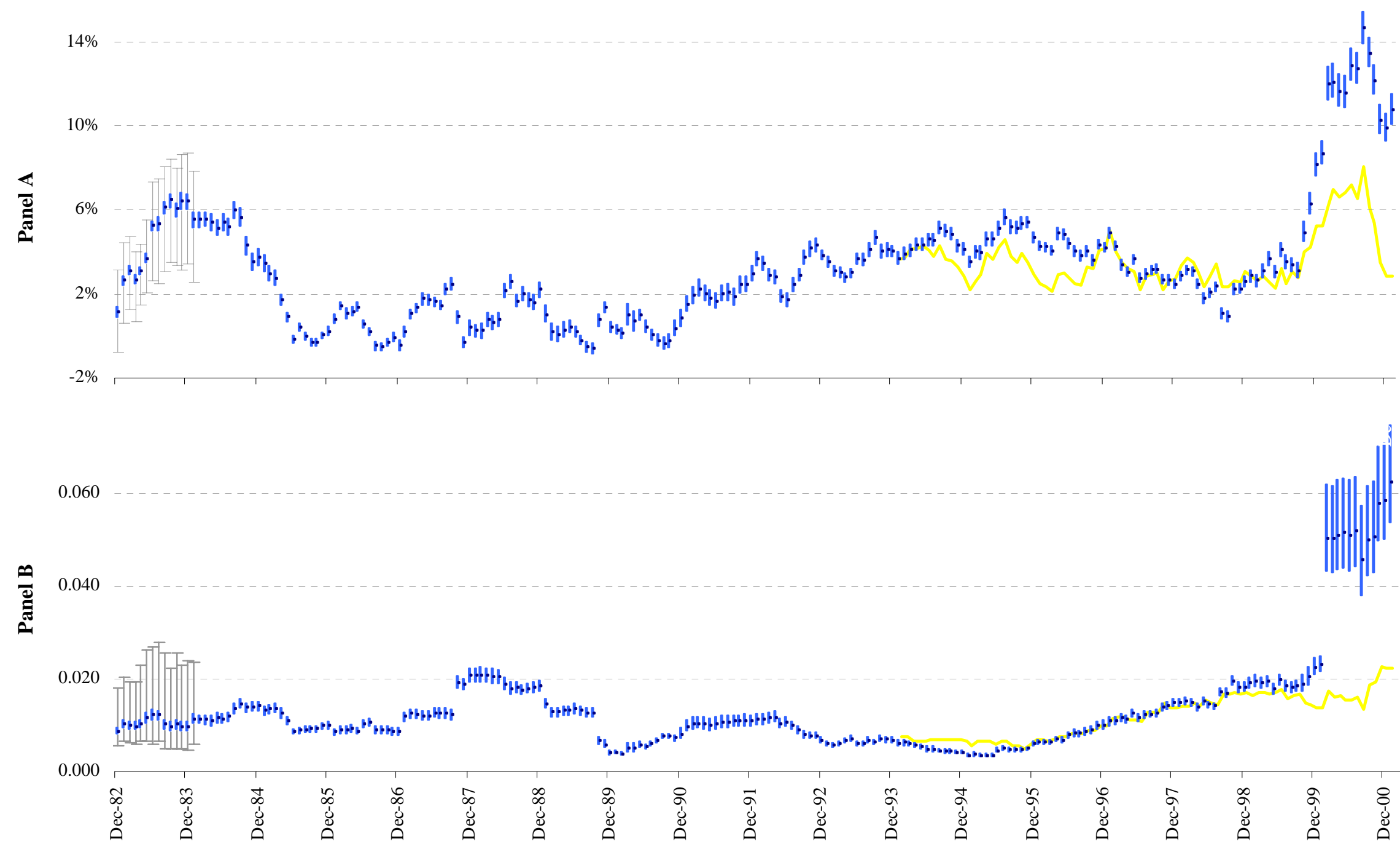


\section{Figure 5: Distributions of mining portfolios}

For the period December 1982 through January 2001 some statistics of the mining portfolios distribution are presented. Panel A shows the distribution of returns in mining portfolios and panel B presents shows the distribution of portfolio variances for the same period. The dot on the bar represents the median value of the distribution. The length of the fat bar represents the return range of the middle 50\% of all portfolios. The thin bar (only shown for a few months at the beginning of the period studied) represents the return range capturing all generated portfolios.

$14 \%$

$10 \%$
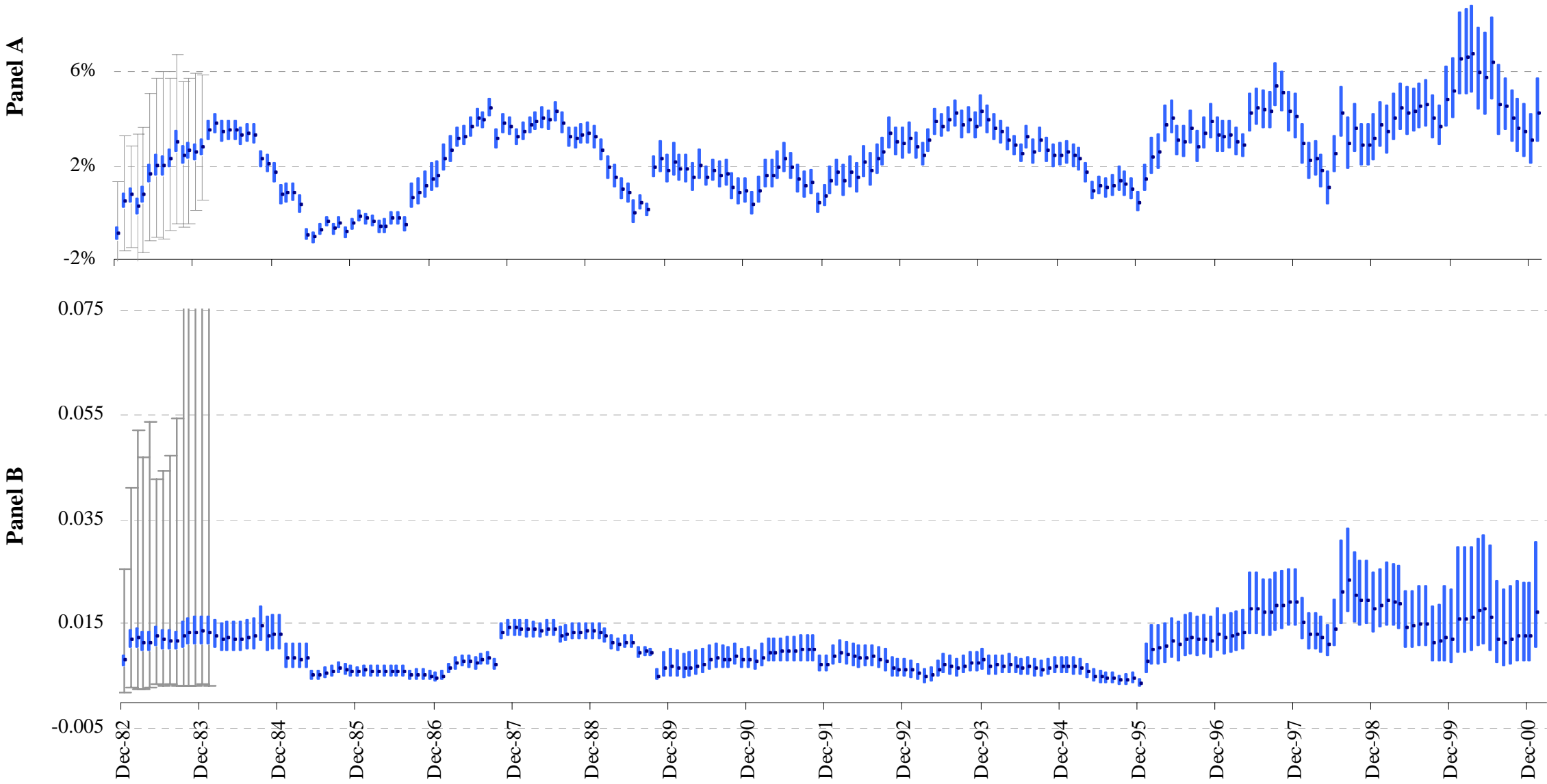
of returns (in panel A) and the variances of the index (in panel B). Figure 5 gives similar graphs for the mining industry. ${ }^{1}$

The graphs clearly reflect several characteristics of the boom during the late nineties. Other episodes, like the period around the $1987 \mathrm{crash}$, can be recognized as well. In interpreting the graphs one should remember that for any given period, all portfolio characteristics are estimated using the 24 preceding observations. ${ }^{2}$ The boom in the late nineties shows rapidly increasing median returns for both sectors, be it that the pace of growth was much higher in the semiconductors sector. Looking at the development of the $50 \%$ middle return range, one sees that in both sectors this range is increasing over time. This signals an increasing heterogeneity in each of the two sectors. The 50\% middle return range in the mining sector is clearly larger than the comparable range in the semiconductors sector. This may be explained by the fact that the mining industry is increasingly less diversified than the semiconductors industry, notably after 1989 (cf. Figure 1). When we compare the graphs that show the development of the portfolio variances, we observe that the median variance is quite stable until the mid nineties, after which they start to grow in both sectors. The increase of the median portfolio variances in the semiconductors sector at the beginning of 2000 is remarkable. After 1989 again, the variance in the semiconductors sector is consistently higher than the variance in the mining industry. In contrast, there is more heterogeneity in the mining sector - now in terms of portfolio variances - than in the semiconductors sector, for the entire period. Again, this may be explained by the lower degree of diversification in mining.

To gain some insight in the asymmetry of portfolios of stocks, we have estimated both the positive and the negative semivariance of each of the generated portfolios. The results are summarized in Figure 6. The two graphs in Figure 6 are constructed by connecting the medians of 218 consecutive distributions, which is like connecting the dots in Figure 4 and Figure 5 respectively.$^{3}$ The first graph shows the development over time of the median of the negative semivariance distributions for both the semiconductors and the mining industry. The second graph shows the development of the median of the positive semivariance distributions. Apart from the last five years, the two sectors do not seem to behave very differently. For the period until 1995 it is hard to conclude from the graphs whether the positive or the negative semivariance is higher on average. However, after 1995 it is clear that the portfolios' positive semivariances win from the portfolios' negative semivariances. This is true for both industries.

Another way of gaining insight in the skewness of portfolio returns is to follow particular portfolios over time. Figure 7 shows the frequencies of the median portfolio realized returns over the entire period. When we compare the entire period, the performance of the two industries is quite different. The median portfolio returns distribution of semiconductors is more asymmetrical than the mining portfolio. For the

\footnotetext{
${ }^{1}$ The Dow Jones US Mining index consists of only one stock in December 2002. Thus it can be hardly used for comparison.

${ }^{2}$ We do not use the exponential smoothing.

${ }^{3}$ We do not show the complete distributions of the semivariances in order to save journal space. Readers who require more information are kindly invited to contact the authors.
} 
Figure 6: Median semivariances of semiconductors and mining portfolios

For the sample period December 1982 - January 2001 (218 months) the negative and positive semivariance distributions of the two industry sectors are calculated. Panel A shows the medians of the negative semivariance distribution of semiconductors and mining. Panel B gives the medians of the positive semivariance distribution for both industries.

Panel A: Medians of the negative semivariance distributions

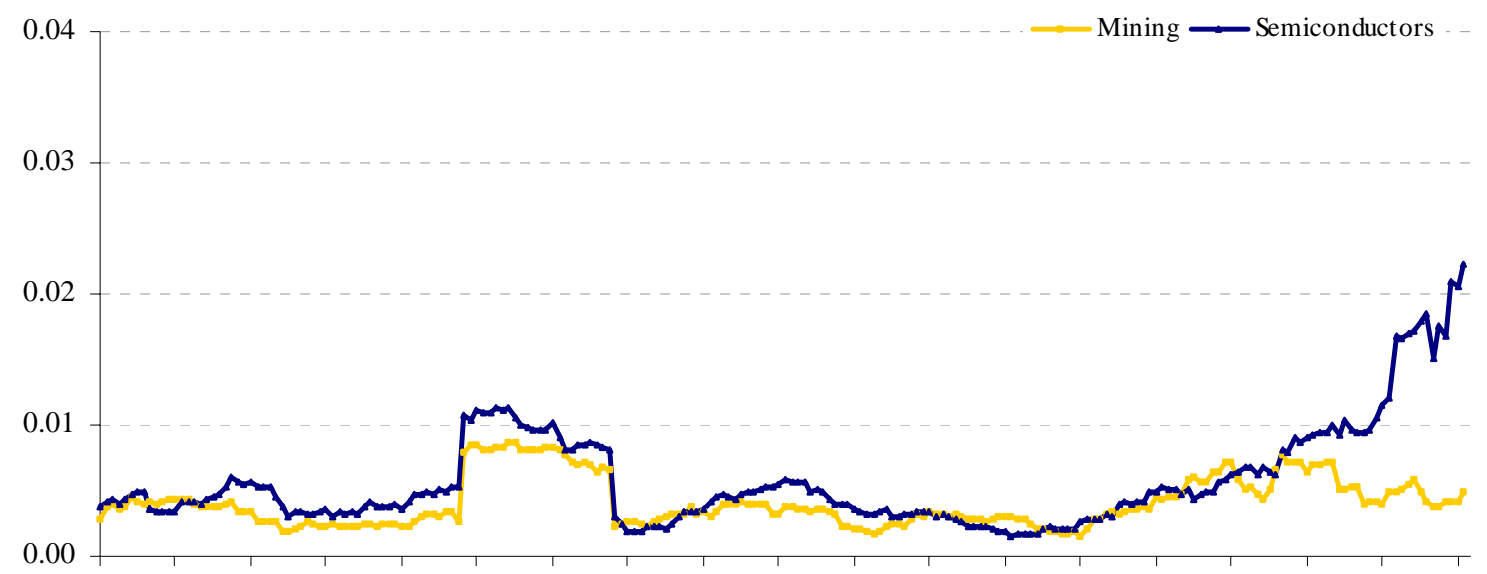

Panel B: Medians of the positive semivariance distributions

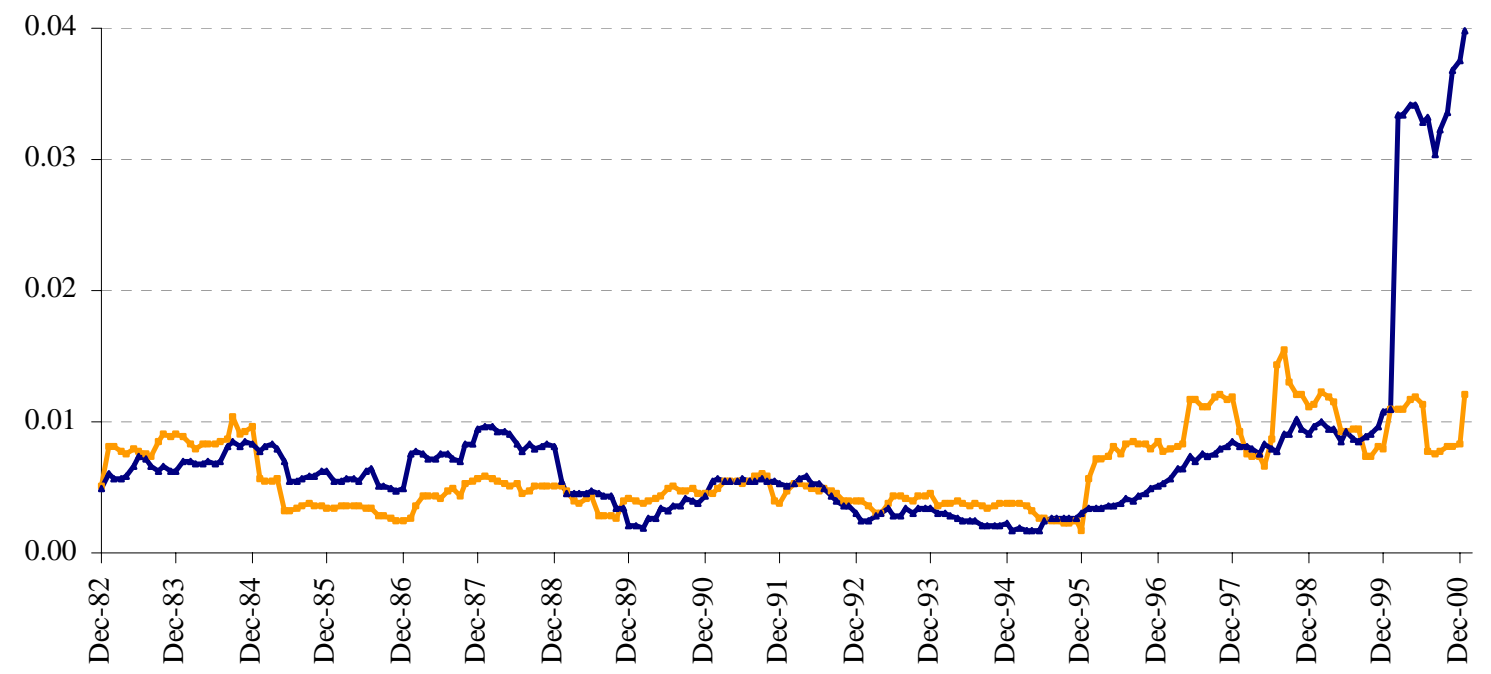

sample period December 1982 - January 2001 (218 months) the median returns of the two industry sectors are calculated. Panel A shows the time series median returns of the semiconductors and panel B gives the median returns of mining. The average median return of the semiconductors $(3.36 \%)$ distribution is higher than the average of mining $(2.08 \%)$. The standard deviation in median returns of semiconductors (12.72) is also higher than the standard deviation of mining (9.03). The distribution in Panel A is more asymmetrical (Skewness: 6.78) than the distribution of panel B (Skewness: 5.24). However, if we leave out the last 25 observations (the boom period), the differences between the arithmetic means and the standard deviations of the two distributions become smaller. However, the skewness of the mining industry is higher than in the 
Figure 7: Median monthly portfolio returns of semiconductors and mining

Panel A shows the median returns of the semiconductors sector for the entire period of 218 months (upper part of panel A) and for the entire period without the 25 booming months, leaving 192 months (lower part of panel A). In panel B we show the results for the mining sector.

Panel A: Semiconductors
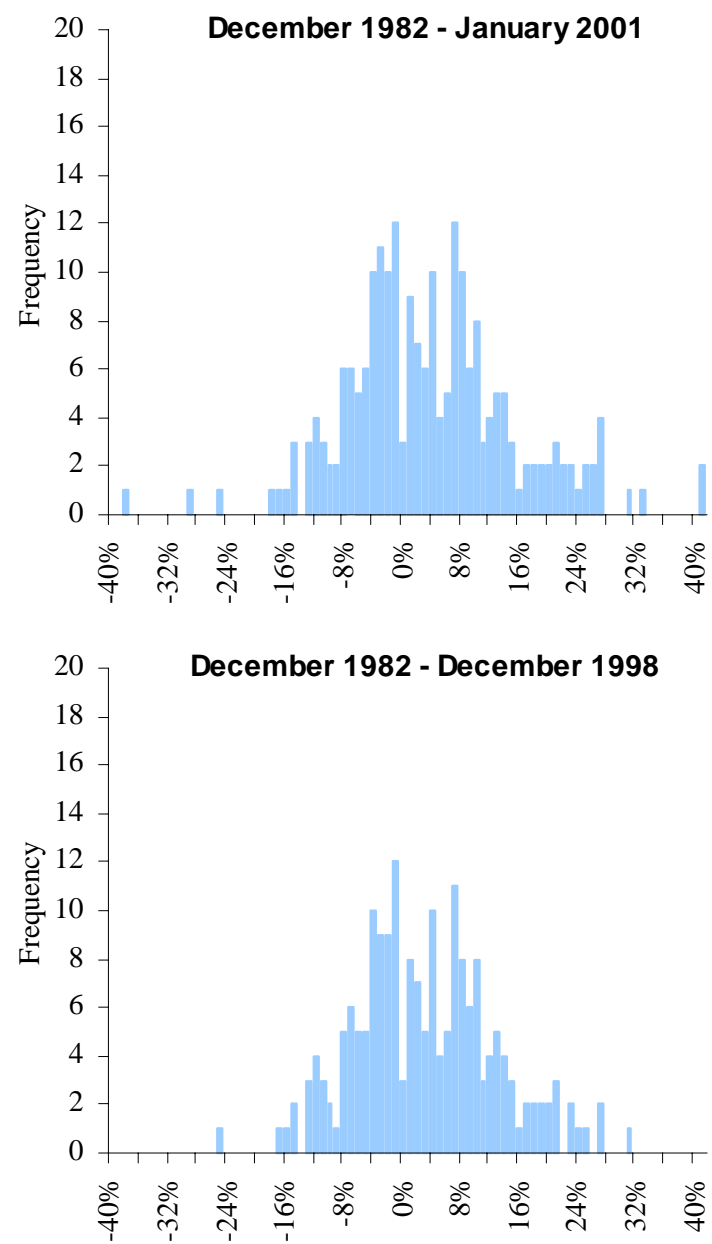

1982-2001 $(\mathrm{n}=\mathbf{2 1 8})$

$\begin{array}{lc}\text { Average } & 3.36 \% \\ \text { Standard deviation } & 12.72 \% \\ \text { Skewness } & 6.78\end{array}$

1982-1998 $(\mathrm{n}=192)$

$\begin{array}{lc}\text { Average } & 2.58 \% \\ \text { Standard deviation } & 9.65 \% \\ \text { Skewness } & 3.71\end{array}$

Panel B: Mining
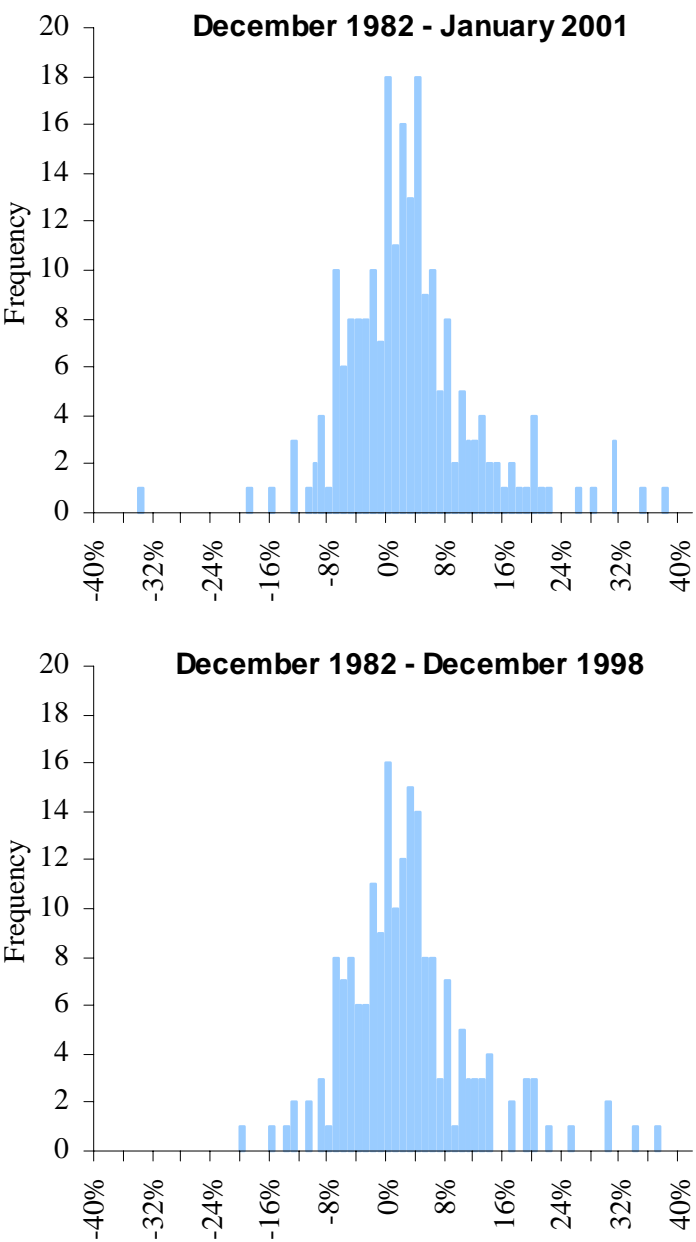

1982-2001 (n=218)

$\begin{array}{lc}\text { Average } & 2.08 \% \\ \text { Standard deviation } & 9.03 \% \\ \text { Skewness } & 5.24\end{array}$

1982-1998 $(n=192)$

$\begin{array}{lc}\text { Average } & 2.13 \% \\ \text { Standard deviation } & 8.53 \% \\ \text { Skewness } & 5.82\end{array}$

case of 218 observations (as shown in the lower part of panels A and B) while the skewness of the semiconductors is much lower than before and also considerably smaller than the skewness of the mining industry. This underlines the importance of the size and unbalanced changes in the semiconductors sector during the boom period. 


\section{CONCLUSIONS}

Empirical evidence suggests that stock returns are not normally distributed. The above results suggest this is also true for portfolios of stocks. In fact both median industry portfolio have fat tailed and positively skewed return distributions. During the boom period (1999-2000), the semiconductors industry showed an enormous increase in skewness.

The graphs in Figure 4 on the development of the performance of semiconductors portfolios can be compared with similar graphs of the mining industry in Figure 5. We made this comparison in terms of four different performance measures: return, variance and both negative and positive semivariance (the latter two in Figure 6). Much to our surprise, the two industries behaved very similar for most of the period (actually until the beginning of the boom) in terms of all the performance measures used.

The last two years in our sample, the two booming years before the bust, the performance of the two industries was quite different. In the mining industry there seems to be a moderate build-up of average returns over time and a somewhat higher variance during the last few years. In contrast, the developments in the semiconductors industry are truly extraordinary. The average returns show an enormous growth, as do the average portfolio variances and both positive and negative semivariances. It is important to note that the upside semivariance in the semiconductors industry grows twice as fast as the downside semivariance during this period. This suggests that the differences between the firms within this industry, seen through the eyes of the investors, are getting bigger and bigger throughout this period.

When comparing positive and negative semivariance, the positive part seems to beat the negative almost continuously. An important exception is right after the 1987 stock market crash when the negative semivariance was winning for some time. In the near future, we will further investigate whether the millennium bust shows the same pattern as the period after October 1987. The same holds for the minor crashes in between.

In this article, a new way of looking at the stock market performance of different industries and their differences has been introduced and illustrated. A number of refinements and extensions can be made. One example is to change the way the variances and semivariances are estimated. Presently, each data entry gets the same weight in estimating these characteristics. Because of the depreciation of the information quality of older data, exponential smoothing of the data might be considered, next to other techniques with similar effects. But first and foremost we will extend our dataset. One may question whether a clear distinction between 'new economy' and 'old economy' or between 'high growth' and 'low growth' stocks can be defined. We tend to believe that the differences between the industries are more gradual. We hope to shed more light on this issue by also analyzing and comparing other industries. 


\section{REFERENCES}

Fama, Eugene F. (1965) The Behavior of Stock Market Prices. Journal of Business 38 : 34-105

Groenendijk, Aart and Jaap Spronk (1999) Portfolio Performance through the Eyes of Monkeys. In: Maria Bonilla et al (eds) Financial Modelling. Physica-Verlag, Heidelberg, pp 203-213

Hallerbach, Winfried, Christoph Hundack, Igor Pouchkarev and Jaap Spronk (2002) A Broadband Vision of the DAX over Time. (Report by Erasmus Research Institute of Management, ERS-2002-87-F\&A, available at http://www.eur.nl/WebDOC/doc/erim/erimrs20021008171714.pdf )

Harvey, Campbell R., and Siddique Akhtar (2000) Conditional Skewness in Asset Pricing Tests. Journal of Finance 55: 1263-1295

Kester, Carl W. (1984) Today's options for tomorrow's growth. Harvard Business Review, March-April: 153-160

Knez, Peter J., and Mark J. Ready (1997) On the Robustness of Size and Book-tomarket in Cross-sectional Regressions. Journal of Finance 52: 1355-1382

Kon, Stanley J. (1984) Models of Stock Returns- a Comparison. Journal of Finance 39:

147-165.

Kraus, Alan and Robert Litzenberger (1976) Skewness Preference and the Valuation of Risky Assets. Journal of Finance 31: 1085-1100

Pouchkarev, Igor (2004) A General Framework for the Evaluation of Constrained Portfolio Performance, PhD Thesis, Erasmus University Rotterdam, to appear

Trigeorgis, Lenos (1996) Real Options: Managerial Flexibility and Strategy in Resource Allocation. MIT Press, Massachusetts 


\section{Publications in the Report Series Research ${ }^{*}$ in Management}

ERIM Research Program: "Finance and Accounting"

\section{3}

COMMENT, Risk Aversion and Skewness Preference Thierry Post and Pim van Vliet ERS-2003-009-F\&A

Portfolio Return Characteristics Of Different Industries Igor Pouchkarev, Jaap Spronk, Pim van Vliet ERS-2003-014-F\&A

A complete overview of the ERIM Report Series Research in Management: http://www.ers.erim.eur.nl

ERIM Research Programs:

LIS Business Processes, Logistics and Information Systems

ORG Organizing for Performance

MKT Marketing

F\&A Finance and Accounting

STR Strategy and Entrepreneurship 